\title{
ANALYTICAL REVIEW OF THE VALUE ENGINEERING METHODOLOGIES AND SELECTING SUPERIOR METHODOLOGY BASED ON TOPSIS MULTI-CRITERIA DECISION
}

\author{
Saeed Asgari \\ Master of Project Management and Construction, University of Tehran, Iran \\ saasgari@ut.ac.ir
}

\begin{abstract}
Value engineering is one of the management tools which has been used in recent decades and is defined as a set of systematic techniques, based on creativity and teamwork to solve problems that are applied to reduce costs and performance improvements and quality of the project, products and processes. The application of this tool is preferable to manage the minds of experts in order to create Brainstorm and valuable ideas and provides creativity in order to modify the system. Generally, value engineering includes ancillary advantages such as the creation of synergy in the organization, improve communication between design factors, take advantage of applicable ideas in similar projects, increase teamwork spirit within the organization, trading beneficial factors functionalist design thinking and promote creative thinking and deconstructing in addition to its original benefits including improving design quality and reduce costs. Although the engineering value are provided about fifty years ago in developed countries, to analyze the performance of a product or service and provide an acceptable option with the lowest cost and used in various projects, but in our country only in recent years the importance of this subject is addressed and the first steps have been taken for its application. Also noteworthy based on studies in this context, it can be concluded that according to the modern methods of value engineering in comparison with previous methods, value engineering positions at top management levels are placed and encircles all a system of senior executives and clerks. In this study at first, value engineering definition is reviewed from the perspective of institution and various researchers and finally by adopting a comparative evaluation between different methodologies based on expert opinion and industry experts, the most appropriate methodology will be introduced to use in projects within the country through applying multi-criteria decision making on TOPSIS method.
\end{abstract}

Keywords: Value engineering, Cost reduction, Quality, Creativity, Topsis

\section{INTRODUCTION}

Value Analysis was adopted as a special technical method in the years after World War II. Particularly, design and development of this method is commenced by Henry Erlicher "Technical Assistant of General Electric Company purchases". He believed that some of the materials and alternative proposals that were employed essentially and Due to wartime shortages have had a better performance at a lower cost. According to his command within the company and to improve production efficiency through supply of materials, components and alternatives approached for materials and costly materials, a concerted effort was made. In 1947, this task was founded to Lawrence D.Miles "Chief engineer of General Electric Company". Miles has been studied about the available methods and techniques and exploited some conventional methods for compilation with its step by step approach to value analysis. Miles who is considered the initiator and founder of Value Engineering, provided a formal approach into practice that were examined several groups of employees, Performance of GE's products. They rely on a group of creative methods and without compromising product performance, created changes in the company's products and didn't reduce production costs. Hence, "value" analysis was accepted as a standard in the General Electric Company and gradually other companies and some government agencies applied this new approach as a means to reduce their costs. The result was concluded in such a way that "value engineering" technique improved. Value engineering is one of the management tools which has 
been used in recent decades and is defined as a set of systematic techniques, based on creativity and teamwork to solve problems that are applied to reduce costs and performance improvements and quality of the project, products and processes. Value engineering provides applicable product or process improvements to quickly meet the results by contribution of a wide range of professional's knowledge and experience and focuses on the functions of the project. According to the definition of International Project Management Institute, value engineering is a creative attitude to optimize life cycle costs, saving times, increase profits, improve quality, increase market share, and solve problems and optimal use of resources. In terms of Zimmerman viewpoint, value engineering is management strategy and creative idea seeking to provides the best trade-off between cost, validity and reliability of the product or project using functional systems approach (1). According to American standard, value Engineering is defined as application of Systematic techniques and well-known techniques that can calculate functions of a product or service and determine the value of these functions, the most essential functions to achieve real performance of products at the lowest cost during the life cycle (2). Ernst Bouy President of Value Engineers Association in America believes that: Value Engineering is not only may not give priority to a certain elements, but also is a kind of approach to think. Figure 1 show the cycle of value engineering in a simple language.

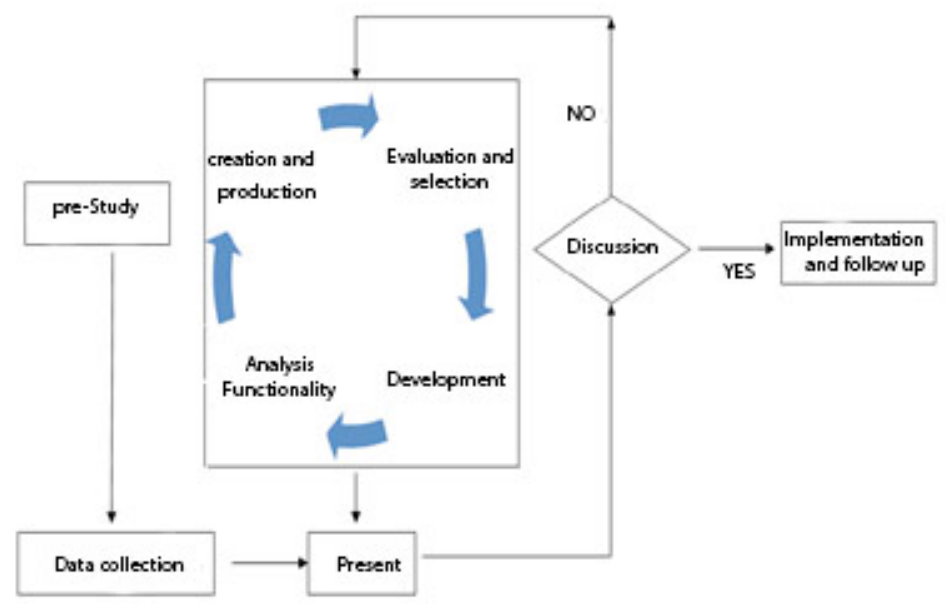

Figure 1: Cycle of Value Engineering

\section{COMPARISON OF VALUE ENGINEERING WITH OTHER METHODS OF IMPROVEMENT IN THE MANAGEMENT}

As it is clear from the definition of value engineering, Strengths of Value Engineering against other approach utilized to reduce costs and improve the quality, is that this method is focused on the functions of the project or product and taking advantage of group creativity and its synergy to provide applicable solutions in the shortest possible time. The Matrix tool compares the features of several management methods and provides a methodology for evaluating of these methods. The method used in this comparison is based on five options. Obviously, if a way for an application is appropriate in particular, the number of 5 is awarded; if is useful for one application but is not its primary usage of this method, number 4 is assigned; if method has little application number 3 and number 1 or 2 indicates the lack of usefulness this method correlating to intended user (3). 
Table 1: Comparison of Different Methods of management Improvement

\begin{tabular}{|c|c|c|c|c|c|c|c|c|c|c|c|c|c|c|c|c|}
\hline Comparison Matrix & 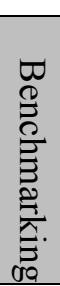 & $\underset{\varpi}{\mathbb{W}}$ & $\stackrel{1}{\longrightarrow}$ & 빔 & ○ी & 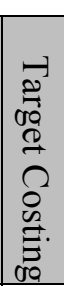 & $\begin{array}{l}-1 \\
\Omega \\
\Omega \\
\varrho \\
\Omega \\
\Xi \\
\Xi\end{array}$ & 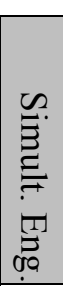 & $\stackrel{0}{0}$ & 3 & 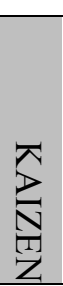 & 死 & 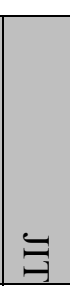 & $\underset{3}{3}$ & $\underset{T}{\nabla}$ & $\begin{array}{l}\infty \\
\vdots \\
\omega \\
\overrightarrow{0} \\
3\end{array}$ \\
\hline Organization of design & & & u & & & & & $\omega$ & & $u$ & & & & & & $>$ \\
\hline Skills development & & & un & & & & & + & 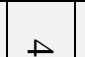 & $\Delta$ & un & ur & & & & $\varpi$ \\
\hline Simplification functions & & & ur & & & & & & & $\omega$ & $A$ & & & & & 0 \\
\hline Organizing and operating & & & ur & & & & & & & u & + & & 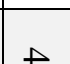 & & & $\forall$ \\
\hline Improve production costs & $\triangle$ & & us & 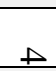 & & un & $\perp$ & $\omega$ & \pm & & $\omega$ & $\omega$ & + & & ur & $(\pi)$ \\
\hline Budget control & & $\perp$ & & & & us & + & w & + & & & & & & + & $\pi$ \\
\hline Improve product & 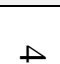 & & ur & ur & ur & & ur & $\omega$ & ur & & & 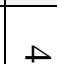 & & & & $\Omega$ \\
\hline Creating new ideas & + & & us & us & & & & & A & & ur & & & & & $I$ \\
\hline The development of & & & un & & & & & & & & & & & & & \\
\hline Improve production & & & $\perp$ & & ur & & ur & & $D$ & & us & & & $\triangle$ & & 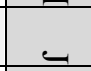 \\
\hline Improve production & $\triangle$ & & $u_{1}$ & & un & $\perp$ & u & & $\omega$ & & + & & ur & u & ur & $\pi$ \\
\hline Improve administrative & & un & ur & & ur & + & & $D$ & $\omega$ & ur & & & us & & ur & $\Gamma$ \\
\hline Problem solving & & & ur & ur & $\perp$ & & $\omega$ & & $\perp$ & & & ur & & & $\omega$ & 3 \\
\hline Information Development & & & $A$ & & & & & & ur & & & & & & & $z$ \\
\hline Improve product & & & + & & $\triangle$ & & ur & & & & & & & ur & & 0 \\
\hline Reducing the number of & & & $u_{1}$ & & & & & & $\triangle$ & & & & & & & $\tau$ \\
\hline available Software & & & $\omega$ & ur & & & & & & & & & & & & 0 \\
\hline Structured process & & & & us & & & & & ur & & $\Delta$ & un & & 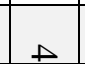 & ur & $\pi$ \\
\hline Activity-based process & ur & 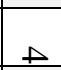 & $\perp$ & + & $u_{1}$ & un & ur & ur & $u_{1}$ & ur & u & u & ur & & u & $\sim$ \\
\hline \multirow[t]{3}{*}{ The process is based on } & & ur & $u_{1}$ & & & & & & & & & & & & & $\rightarrow$ \\
\hline & $n$ & $\vec{\infty}$ & $\stackrel{\infty}{+}$ & $N$ & 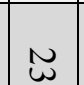 & $\underset{\omega}{N}$ & $\omega$ & $n$ & y & $\mathcal{y}$ & $\omega$ & I & 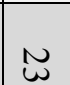 & $\vec{\infty}$ & $\underset{N}{\omega}$ & $\geq \widehat{0}$ \\
\hline & 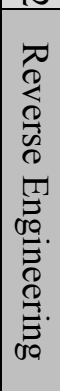 & 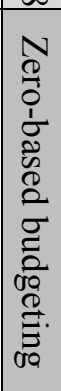 & 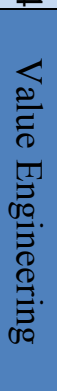 & $\begin{array}{l} \\
\\
\overrightarrow{0} \\
0 \\
0 \\
0 \\
0 \\
0 \\
0\end{array}$ & 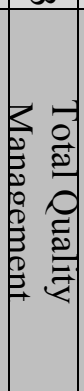 & 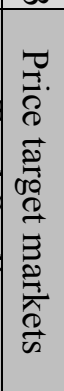 & $\begin{array}{l}\sigma \\
0 \\
0 \\
0 \\
0 \\
0 \\
0 \\
0 \\
0 \\
0 \\
3\end{array}$ & 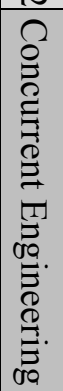 & 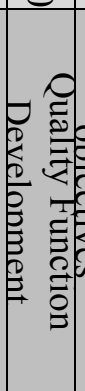 & 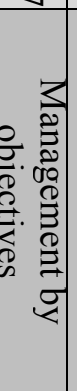 & 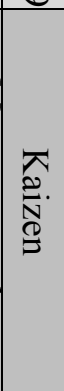 & 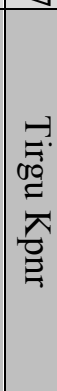 & 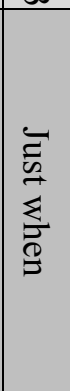 & 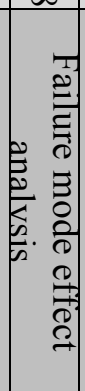 & 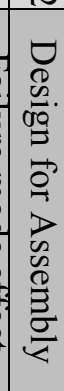 & 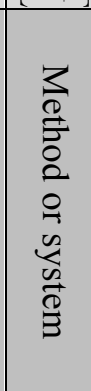 \\
\hline
\end{tabular}




\section{APPROPRIATE TIME OF APPLYING VALUE ENGINEERING}

Value engineering is applicable at all stages of a project, but the most benefits is achieved in the early stages of planning and project design where Flexibility of employer and designer is high, operation modifications are easier, and the impact of changes on project schedules is less and imposes a lower cost to the project. According to the International Society of Value Engineering, most profit and economizing on resources is obtained in the early stages of development and during the conceptual stages. At this stage, preliminary data of project is created, but the original design and resource development are not yet been conclusive. Due to this fact, this stage is best time to use value engineering where the main functions of the project is not realized and alternative methods can be taken into account (4).

The value methodology can be used more than once in the project life cycle. The initial application of value methodology is contributing the project started in the right direction and its repeated applications will help to correct the course of the project based on new or changed information. When a study of value is executed in late-stage development of the project, it is more likely to increase the costs of implementing (5).

As aforementioned, it can be concluded that whatever value engineering is studied closer to feasibility and initial steps of project, it will effectively enhance benefits of the project. Hence, the Vice President of Strategic Planning and Supervision in Value engineering studies at the instructions Pre-commissioning, operation and construction has recommended one study of value for small projects (At a cost of 20 to 100 billion riyals), two study for medium projects (at a cost of 100 to 300 billion riyals) and five value study for large projects (at a cost of 300 to 800 billion riyals) and very large (at a cost of more than 800 billion) in which at least one study is Mandatory for all the medium, large and very large projects (6).

Table 2: define Dimensions of the project

\begin{tabular}{|c|c|}
\hline Estimated project cost & $\begin{array}{c}\text { The size of the project or } \\
\text { projects }\end{array}$ \\
\hline $\begin{array}{c}\text { Small } \\
\text { More to } 100 \text { billion rials } 100 \text { to } 300 \text { billion } \\
\text { rials }\end{array}$ & medium \\
\hline 300 to 800 billion rials & Large \\
\hline More than 800 billion rials & Very large \\
\hline
\end{tabular}

Table 3: Number of proposed value and the duration of their studies

\begin{tabular}{|c|c|c|c|c|c|c|c|}
\hline \multicolumn{4}{|c|}{ Detailed design } & \multirow{2}{*}{$\begin{array}{l}\text { The final } \\
\text { feasibility } \\
\text { study and } \\
\text { preliminary } \\
\text { design }\end{array}$} & \multirow{2}{*}{$\begin{array}{c}\text { The initial } \\
\text { feasibility } \\
\text { study }\end{array}$} & \multirow[b]{2}{*}{ start } & \multirow{2}{*}{$\begin{array}{l}\text { The size of } \\
\text { the project } \\
\text { or projects }\end{array}$} \\
\hline end & $\begin{array}{c}\% 75 \\
\text { improvement }\end{array}$ & $\begin{array}{c}\% 50 \\
\text { improvement }\end{array}$ & $\begin{array}{c}\% 25 \\
\text { improvement }\end{array}$ & & & & \\
\hline & & & & $\begin{array}{c}\text { 3-5 day } \\
\text { optional } \\
\text { workshop }\end{array}$ & & & small \\
\hline
\end{tabular}




\begin{tabular}{|c|c|c|c|c|c|c|c}
\hline \multicolumn{2}{|c|}{$3-5$ day optional workshop } & $\begin{array}{c}3 \text {-5 days } \\
\text { workshop } \\
\text { compulsory }\end{array}$ & medium & & Large \\
\hline & $\begin{array}{c}3-5 \text { day } \\
\text { optional } \\
\text { workshop }\end{array}$ & $\begin{array}{c}3-5 \text { day } \\
\text { optional } \\
\text { workshop }\end{array}$ & $\begin{array}{c}\text { 5-day optional } \\
\text { workshop }\end{array}$ & $\begin{array}{c}5 \text {-day } \\
\text { workshop } \\
\text { compulsory }\end{array}$ & $\begin{array}{c}\text { 3-day } \\
\text { Optional } \\
\text { workshop }\end{array}$ & & Very large \\
& $\begin{array}{c}3-5 \text { day } \\
\text { optional } \\
\text { workshop }\end{array}$ & $\begin{array}{c}\text { 3-5 day } \\
\text { optional } \\
\text { workshop }\end{array}$ & $\begin{array}{c}\text { 5-day } \\
\text { workshop } \\
\text { optional }\end{array}$ & $\begin{array}{c}\text { 5-day } \\
\text { workshop } \\
\text { compulsory }\end{array}$ & $\begin{array}{c}\text { 3-day } \\
\text { workshop } \\
\text { compulsory }\end{array}$ & & \\
\hline
\end{tabular}

\section{VALUE ENGINEERING AND CONSTRUCTION SECTOR}

There are many problems in the implementation of the project focused on three factors: time, cost and quality so that these challenges may enhance the importance of executable and reliable mechanisms for applications of the world sciences. In addition to necessity of these legal requirements in the application of value engineering in State and national projects, the need for a comprehensive, pervasive and applicable approach is sensed which could pave the way for project managers and experts. Evaluation of construction development projects according to the information and progress reports of national development projects have been published by Management and Planning organization during the years of 1995-2002 indicates that fulfilling of the realization of the projects in mentioned period at best case will be 49.5 percent (2000). Weighted average term respect to implementation of development projects in these mentioned years at best were 7.7 years (almost twice the predictions made in the design phase). On the other hand, the quality of the project implementation was inadequate and only $3.2 \%$ of projects terminated in 2002 contained higher quality grade. The statistics of the year 2001 (as an example) shows that in this year 670 thousand billion Rials credit is intended to implement 8892 projects. In this year, about 60.1 percent of predicted development credits have been allocated (10\% less than 2000) and 59.7 percent of annually targets for National projects are realized. Moreover, 64.5 percent of the projects are lagged behind schedule and 41.5 percent of projects that were required to be operated were finished. Figures of rows annual budget in Construction development demonstrate the existence of appropriate situation to apply Value engineering. The status of Construction development projects in our country is insufficient in terms of design, implementation methods and standards against countries that enforced their organizations to apply Value engineering. If we consider implementing scientific and engineering community with these countries, we can understand that Value engineering tools can be a procedure to reduce government expenditure on administrative activities. The application value engineering in civil and architecture is important for this aspect that in addition to improving the quality of projects, may create added values and financial savings especially in the area of housing so that it's increasingly applications in the world is visible.

\section{VALUE ENGINEERING FROM DIFFERENT PERSPECTIVES}

Value Engineering Society in Japan which is in operated since 1965 defines value engineering as follows: Value Engineering is team-oriented and functional approach in order to analyze and improve value in a product, Plan or service (7). Fodor states value engineering, Value analysis, value management, value planning, value reliability or any other term as very powerful method is adopted to reform and improve the system (8). Army engineering corps defined value engineering as investigation of instructions, organizational structures and management systems (9). University of Leeds also defines value engineering as whole value improvement process for the customer from the determination of concepts to the operation of project (10). Particularly, A.F.A.V is a French association that is designed to promote and advance the methods of value engineering so that the scope of this forum activity is applying value engineering techniques alone or in combination with other methods. These activities include the training and consulting (11). C.S.V.A or Value Engineering Association of Canada located in Canada and is defined its mission as follows: Promote the use of methodologies to value their own interests to 
governments, industry, professionals and associations. This Association has presented its business philosophy bilingual website in French and English language: learning other methodologies and the right combination of value analysis with other techniques and research and development of other approaches and methodologies that are related to association missions (12). I.V.M or Institute of Value Management which is established in the UK has several branches in the world. This Institute has launched a complete website and encompasses a lot of activity related to management of value (13). V.D.I that was founded as the engineering Society in 1956 is an independent and autonomous organization, apolitical and non-profit. The members of this association are more than 126000 engineers and natural scientists and considering an Honorary Fellow of the people are the largest engineering association in the West of Europe (14). The main objective of INVEST or Value Engineering Association of India is maximum Return rates of investments (ROI) from Value engineering (15).

\section{VARIETY OF VALUE ENGINEERING STUDY METHODOLOGY IN THE WORLD}

Methodology applying to value engineering study based on programs offered by various experts transparently is different. Miles firstly in the 7 phases and later during the 5 phases, Mudge in 7 phases, Kempter and Hannan in 8 phases, Fallon during the 6 phases, Dell 'Isola in 4 phases, Attwood in 7 phases and in some cases renowned specialists have executed their studied in 9 phases.

Generally, there are multiple schedules and tasks must be operated by country or the value engineering administrators and on the other hand, it may be each operator modify the programs in the organization due to the nature of the subject. What programs are listed below are examples of standardized programs in different countries or organizations (16).

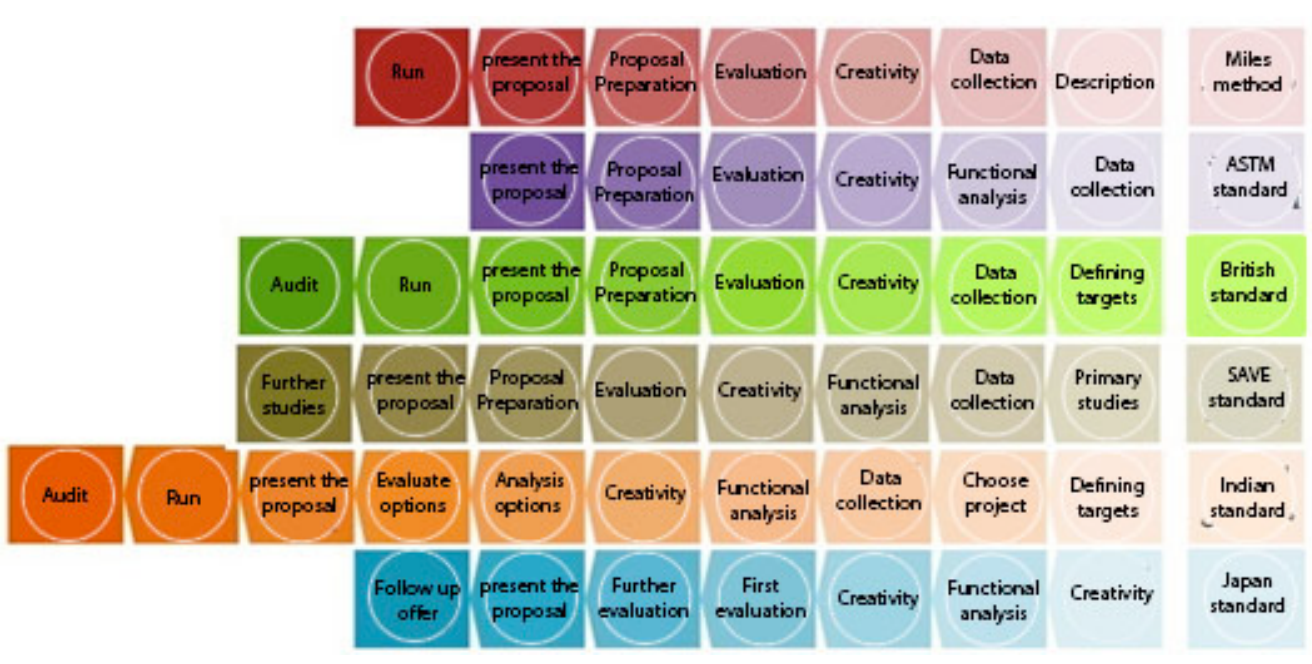

Figure2. Types of value engineering study methodology in the world

As can be seen, this difference is more apparent in the number of phases; because operation of the routines by each group of stakeholders and experts endures a greater or lesser failures and the time to engage in a phase or executing specific activities in the project is earlier or later than others; while the process and team approach and set of necessary activities and their priority and deferment are not considerably difference.

\section{FUNCTION ANALYSIS PHASE: VALUE ENGINEERING HEART}


The lifeblood of value engineering in all methodologies is functional analysis. Actually, the functionalist approach of value methodology discriminate it from other methods and techniques. The objectives of this phase are explained as follows:

ü Creation of a single state between professionals

ü goal-oriented and result-oriented study

ü converting the discussion from the project components to functionalities

ü Analysis and selection of potential areas for improvement (focus on creativity Phase)

ü Increases on understanding of the project team and prepare them for processing practical ideas

Determination and understanding the functionalities are the requirements of each study because all the costs will be consumed for functionalities. Understanding the functionalities of a project may induce and transfer teams and individuals from a public perception to careful and determined and detailed understanding. Indeed, the goal of this phase is to specify explicit limits of the scope of the value in project that will be most beneficial. This phase requires the construction phase and instructions to provide the desired results. Summary of mechanisms and Points that must be considered in this phase are declared as follows:

\section{ü Functions definition}

ü determine Functions and resilient regions

ü Functions classification (primary, secondary, Secondary necessary and unnecessary)

ü providing operational analysis

ü cost analysis and cost of operation

In general, this phase includes all the efforts that are made for value engineering. Meanwhile, defining primary and secondary functions, performance of each component in form of verb and noun is expressed so that verb indicates such action that is operated by desired component and noun indicates the issue concerning what action or actions performed on it (17).

The purpose of this step is to understand the project from the perspective of functional which means what should be operated in the project. Some necessary activities to achieve the goal of this step include (3):

ü determine project functions as determined by means of random functions

ü Categorizing Project functions

ü Development of functional model with tools like Function Analysis System Technique (FAST) and function tree

ü Scaling model with the parameters of cost, performance characteristics and user behavior in order to select non-conforming applications against value to focus on value creation step; the measures used in this case are defined as follows:

$\mathrm{v}$ cost analysis respect to function (function matrix), 
v Performance respect to function

ü cost estimation functions in order to select the value of non-conforming functions and creative focus on them with tools such as Value Index.

Finally, it can be concluded this step confirm that teams are focused on fulfill customer's needs and goals of the project. Moreover, provides more comprehensive understanding of the project to be focused on what the project does or should do and finally the values of non-conforming functions are determined in order to improve the project.

\section{EVALUATE, PRIORITIZE VARIOUS METHODOLOGIES AND DETERMINE THEIR IMPORTANCE}

In this section we review comparative evaluation between different methodology from the perspective of scholars and experts in the building industry using Multiple Criteria Decision Making (the most appropriate methodology) through TOPSIS method in internal projects.

\section{RANKING THE OPTIONS USING TOPSIS}

In this method, $m$ agents or options are evaluated by an individual or group of individual of decisionmakers. This technique is based on this concept that each choice of each factor should include shortest distance with the ideal positive factor (most important) and maximum distance from the ideal negative factor (least important factor); in other words in this method, the distance of a factor is measured from a positive and negative ideal factor and this is a criteria for rating and prioritizing factors. In order to identify factors impacting on the choice of the appropriate method of project value engineering in our country, available documents in several projects are examined and in several stages of interviews with designers, Project managers, Supervisors and visionaries who are directly involved in project implementation, different cases in this field are addressed. Then, along with interviews with experts and industry experts and investigating published articles in this field, effective items in this category are identified a questionnaire is developed on the basis of these categories. The questionnaire reformed and standardized through several stages and finally 13 factors remained in which used nine experts in this field and Likert five scale, as responses including high, relatively high, medium, slow and ineffective that have been weighted in data analysis from 5 to 1 ( 5 for high option, 1 for ineffective option).The method steps include:

$\varnothing$ create a decision-making matrix

In this stage a matrix will be drawn that options are deployed in row and indices in the column and in the last row weight of each o indicators are listed and at the intersection of rows and columns, the importance of each respondent for each of the options is made according to the index. (Table 4)

Table 4: decision matrix (N)

\begin{tabular}{|c|c|c|c|c}
\hline $\begin{array}{l}\text { Indicators } \\
\text { Options }\end{array}$ & $\mathrm{C}_{1}$ & $\mathrm{C}_{2}$ & $\ldots$ & $\mathrm{C}_{\mathrm{n}}$ \\
\hline $\mathrm{A}_{1}$ & $\mathrm{r}_{11}$ & $\mathrm{r}_{12}$ & $\ldots$ & $\mathrm{r}_{1 \mathrm{n}}$ \\
\hline $\mathrm{A}_{2}$ & $\mathrm{r}_{21}$ & $\mathrm{r}_{22}$ & $\ldots$ & $\mathrm{r}_{2 \mathrm{n}}$ \\
\hline$\vdots$ & $\vdots$ & $\vdots$ & & $\vdots$ \\
\hline $\mathrm{A}_{\mathrm{m}}$ & $\mathrm{r}_{\mathrm{m} 1}$ & $\mathrm{r}_{\mathrm{m} 2}$ & $\ldots$ & $\mathrm{r}_{\mathrm{mn}}$ \\
\hline $\mathrm{W}_{\mathrm{j}}$ & $\mathrm{W}_{1}$ & $\mathrm{~W}_{2}$ & $\ldots$ & $\mathrm{W}_{\mathrm{n}}$ \\
\hline
\end{tabular}


$r_{i j}$ is rating index of $\mathrm{I}$ in the $\mathrm{j}$ index and $w_{j}$ is the weight of $\mathrm{j}$ index. The following algorithm provides relations of methods and criteria in Topsis pattern. Moreover, table 5 demonstrates options, and table 6 shows evaluation Criteria and table 7 shows the decision matrix.

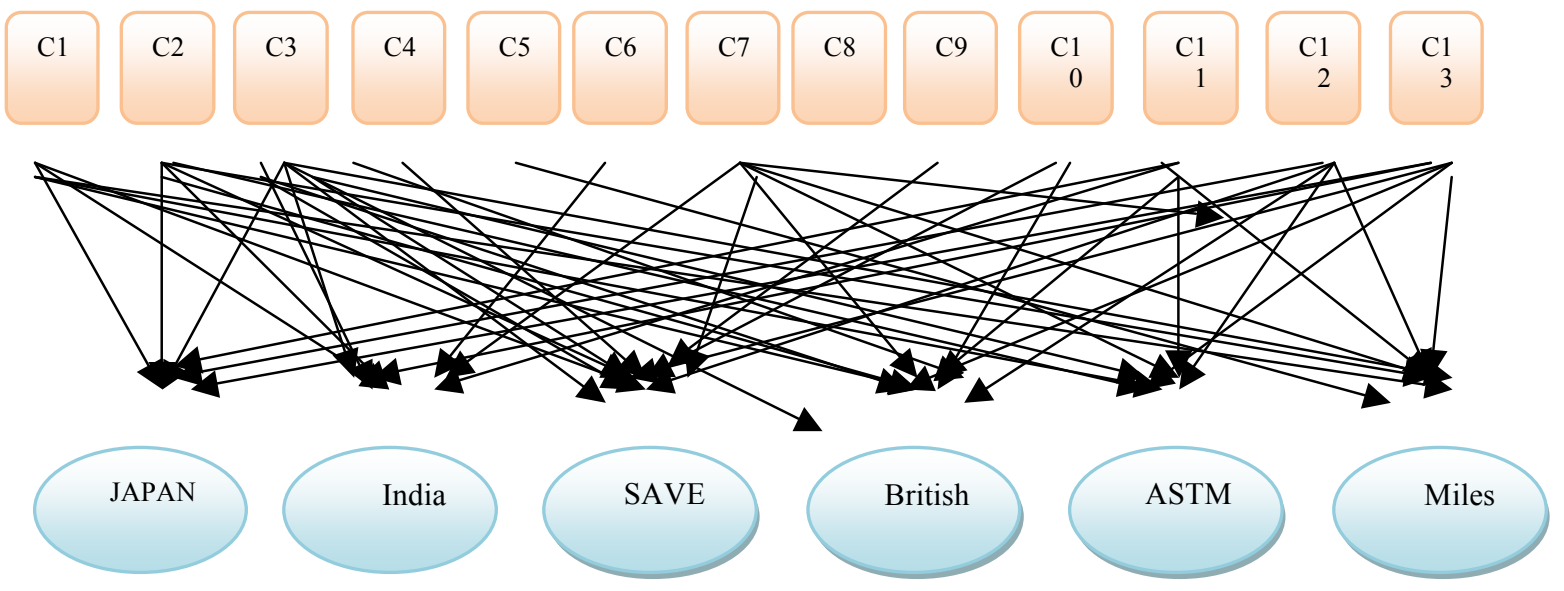

Figure3. Methods relationship algorithm

Table5. Desired options

\begin{tabular}{|c|c|}
\hline Methodology Miles & $\frac{n}{0}$ \\
\hline ASTM standard & A1 \\
\hline British method & A2 \\
\hline SAVE standard & A3 \\
\hline Indian Standard & A4 \\
\hline Japan Standard & A5 \\
\hline Miles Methodology & A6 \\
\hline
\end{tabular}

Table6: Evaluation Criteria

\begin{tabular}{|c|c|}
\hline Project activities & 俤 \\
\hline $\begin{array}{c}\text { Update primary operators, executer, } \\
\text { consumer, stakehoulder }\end{array}$ & $\mathrm{C} 1$ \\
\hline Complement the overall environment & $\mathrm{C} 2$ \\
\hline
\end{tabular}




\begin{tabular}{|c|c|}
\hline Needs analysis and creation of ideas & C3 \\
\hline $\begin{array}{c}\text { Strategic planning project value } \\
\text { determining evaluation factors and the project } \\
\text { horizon }\end{array}$ & $\mathrm{C} 4$ \\
\hline $\begin{array}{c}\text { Quality Policy } \\
\text { Introduction to Project Management Program }\end{array}$ & $\mathrm{C} 7$ \\
\hline Develop performance models & $\mathrm{C} 8$ \\
\hline Costs Modeling & $\mathrm{C} 9$ \\
\hline Ranking and rating of ideas & $\mathrm{C} 10$ \\
\hline Selecting superior ideas & $\mathrm{C} 11$ \\
\hline Range statement & $\mathrm{C} 12$ \\
\hline Development of Project Management Program & $\mathrm{C} 13$ \\
\hline
\end{tabular}

Table7. decision matrix $(\mathrm{N})$

\begin{tabular}{|c|c|c|c|c|c|c|c|c|c|c|c|c|c|}
\hline & C1 & C2 & C3 & C4 & C5 & C6 & C7 & C8 & C9 & C10 & C11 & C12 & C13 \\
\hline $\begin{array}{c}\text { Type } \\
\text { Indic } \\
\text { ator }\end{array}$ & $\begin{array}{c}\text { Posi } \\
\text { tive }\end{array}$ & $\begin{array}{c}\text { Posit } \\
\text { ive }\end{array}$ & $\begin{array}{c}\text { Positi } \\
\text { ve }\end{array}$ & $\begin{array}{c}\text { Posit } \\
\text { ive }\end{array}$ & $\begin{array}{c}\text { Posi } \\
\text { tive }\end{array}$ & $\begin{array}{c}\text { Positi } \\
\text { ve }\end{array}$ & $\begin{array}{c}\text { Posit } \\
\text { ive }\end{array}$ & $\begin{array}{c}\text { Posit } \\
\text { ive }\end{array}$ & $\begin{array}{c}\text { Posi } \\
\text { tive }\end{array}$ & $\begin{array}{c}\text { Posit } \\
\text { ive }\end{array}$ & $\begin{array}{c}\text { Positi } \\
\text { ve }\end{array}$ & $\begin{array}{c}\text { Positi } \\
\text { ve }\end{array}$ & $\begin{array}{c}\text { Posit } \\
\text { ive }\end{array}$ \\
\hline A1 & 6.5 & 5.7 & 7.7 & 6.5 & 7.5 & 8.935 & 6.5 & 6.5 & 6.5 & 6.78 & 4.935 & 5.88 & 6.88 \\
\hline A2 & 5.5 & 5.5 & 5.935 & 6.5 & 7.5 & 7.25 & 5.3 & 5 & 5.5 & 5.85 & 5 & 5.56 & 6.5 \\
\hline A3 & 6.5 & 5.4 & 6.88 & 6.54 & 7.5 & 7 & 5.35 & 4.88 & 7 & 6.85 & 5 & 5.77 & 6.5 \\
\hline A4 & 6.5 & 6.25 & 6.825 & 5.5 & 7.5 & 6.5 & 5.5 & 6 & 5.5 & 6.79 & 7.5 & 6.8 & 7.4 \\
\hline A5 & 8 & 7.5 & 6.88 & 5.5 & 6.5 & 5.5 & 7 & 7.5 & 6 & 7.43 & 7.5 & 8.6 & 8.35 \\
\hline A6 & 6.5 & 7.5 & 7.5 & 7.5 & 6.5 & 6 & 7.5 & 7.5 & 7 & 7.5 & 8.435 & 7.935 & 9.22 \\
\hline
\end{tabular}

Note that the decision matrix is defined as calculus mean of all experts' viewpoints.

- $\quad \mathrm{A} 1$ to $\mathrm{A} 6$ indicated methods and $\mathrm{C} 1$ to $\mathrm{C} 13$ shows criteria.

In order to be comparable values, the decision matrix is converted to non-scale $\left(N_{1}\right)$ matrix using the following equation:

$$
n_{i j}=\frac{r_{i j}}{\sqrt{\sum_{i=1}^{m} r_{i j}^{2}}}
$$

Table 8 shows the non-scale matrix:

Table 8: non-scale Matrix $\left(N_{1}\right)$

\begin{tabular}{|c|c|c|c|c|c|c|c|c|c|c|c|c|c|}
\hline & C1 & C2 & C3 & C4 & C5 & C6 & C7 & C8 & C9 & C10 & C11 & C12 & C13 \\
\hline A1 & 0.334 & 0.298 & 0.361 & 0.34 & 0.353 & 0.452 & 0.32 & 0.345 & 0.35 & 0.344 & 0.253 & 0.285 & 0.296 \\
\hline A2 & 0.283 & 0.287 & 0.278 & 0.34 & 0.353 & 0.366 & 0.261 & 0.266 & 0.296 & 0.297 & 0.257 & 0.27 & 0.28 \\
\hline A3 & 0.334 & 0.282 & 0.323 & 0.34 & 0.353 & 0.354 & 0.264 & 0.259 & 0.377 & 0.348 & 0.257 & 0.28 & 0.28 \\
\hline
\end{tabular}




\begin{tabular}{|c|c|c|c|c|c|c|c|c|c|c|c|c|c|}
\hline A4 & 0.334 & 0.326 & 0.32 & 0.288 & 0.353 & 0.329 & 0.271 & 0.319 & 0.296 & 0.345 & 0.385 & 0.33 & 0.319 \\
\hline A5 & 0.411 & 0.392 & 0.323 & 0.288 & 0.306 & 0.278 & 0.345 & 0.398 & 0.323 & 0.377 & 0.385 & 0.417 & 0.36 \\
\hline A6 & 0.334 & 0.392 & 0.352 & 0.393 & 0.306 & 0.303 & 0.37 & 0.398 & 0.377 & 0.381 & 0.433 & 0.385 & 0.397 \\
\hline
\end{tabular}

To obtain a weighted non-scale Matrix (V), the non-scaled matrix has been multiplied (obtained from previous step) in the square matrix $\left(w_{n \times n}\right)$ that its diagonal elements indicate the index weights and other elements are zero.

$V=N_{1} \times w_{n \times n}$

Table 9 shows the non-scale weighted Matrix.

Table 9: non-scale weighted matrix (V)

\begin{tabular}{|c|c|c|c|c|c|c|c|c|c|c|c|c|c|}
\hline & $\mathrm{C} 1$ & $\mathrm{C} 2$ & $\mathrm{C} 3$ & $\mathrm{C} 4$ & $\mathrm{C} 5$ & $\mathrm{C} 6$ & $\mathrm{C} 7$ & $\mathrm{C} 8$ & C9 & C10 & C11 & C12 & C13 \\
\hline A1 & 0.024 & 0.021 & 0.026 & 0.024 & 0.025 & 0.032 & 0.024 & 0.025 & 0.025 & 0.024 & 0.018 & 0.02 & 0.021 \\
\hline A2 & 0.02 & 0.02 & 0.02 & 0.024 & 0.025 & 0.026 & 0.019 & 0.019 & 0.021 & 0.021 & 0.018 & 0.019 & 0.02 \\
\hline A3 & 0.024 & 0.02 & 0.023 & 0.024 & 0.025 & 0.025 & 0.02 & 0.019 & 0.027 & 0.025 & 0.018 & 0.02 & 0.02 \\
\hline A4 & 0.024 & 0.023 & 0.023 & 0.02 & 0.025 & 0.023 & 0.02 & 0.023 & 0.021 & 0.024 & 0.027 & 0.023 & 0.023 \\
\hline A5 & 0.029 & 0.028 & 0.023 & 0.02 & 0.022 & 0.02 & 0.026 & 0.029 & 0.023 & 0.027 & 0.027 & 0.03 & 0.026 \\
\hline A6 & 0.024 & 0.028 & 0.025 & 0.028 & 0.022 & 0.022 & 0.027 & 0.029 & 0.027 & 0.027 & 0.031 & 0.027 & 0.028 \\
\hline
\end{tabular}

$\varnothing$ determine the positive and negative ideal factor

At this stage we should identify set of choices that respondents characterize as the most important and most trivial factors. In other words, for the positive indicators the positive ideal is greatest amount of $\mathrm{V}$ and negative ideal is the smallest value of $\mathrm{V}$, also for negative indicators, positive ideal is the smallest value of $\mathrm{V}$ and negative ideal is the largest amount of $\mathrm{V}$. The following relationship implies this issue.

positive ideal

$$
A^{+}=\left\{\left(\max _{i} V_{i j} \mid j \in J\right),\left(\min _{i} V_{i j} \mid j \in J^{\prime}\right) \mid i=1,2, \ldots, m\right\}=\left\{V_{1}^{+}, V_{2}^{+}, \ldots, V_{n}^{+}\right\}
$$

negative ideal

$$
A^{-}=\left\{\left(\min _{i} V_{i j} \mid j \in J\right),\left(\max _{i} V_{i j} \mid j \in J^{\prime}\right) \mid i=1,2, \ldots, m\right\}=\left\{V_{1}^{-}, V_{2}^{-}, \ldots, V_{n}^{-}\right\}
$$

In these representations, $J$ implies Positive indicators and $J^{\prime}$ denotes negative indicators.

Table10 shows the positive and negative ideal.

Table 10: positive and negative ideal of each indicator

\begin{tabular}{|c|c|c|}
\hline Criterion & Ideal positive & Ideal positive \\
\hline $\mathrm{C} 1$ & 0.029 & 0.02 \\
\hline $\mathrm{C} 2$ & 0.028 & 0.02 \\
\hline
\end{tabular}




\begin{tabular}{|c|c|c|}
\hline $\mathrm{C} 3$ & 0.026 & 0.02 \\
\hline $\mathrm{C} 4$ & 0.028 & 0.02 \\
\hline $\mathrm{C} 5$ & 0.025 & 0.022 \\
\hline $\mathrm{C} 6$ & 0.032 & 0.02 \\
\hline $\mathrm{C} 7$ & 0.031 & 0.019 \\
\hline $\mathrm{C} 8$ & 0.029 & 0.019 \\
\hline $\mathrm{C} 9$ & 0.027 & 0.021 \\
\hline $\mathrm{C} 10$ & 0.027 & 0.02 \\
\hline $\mathrm{C} 11$ & 0.031 & 0.018 \\
\hline $\mathrm{C} 12$ & 0.03 & 0.019 \\
\hline $\mathrm{C} 13$ & 0.028 & 0.02 \\
\hline
\end{tabular}

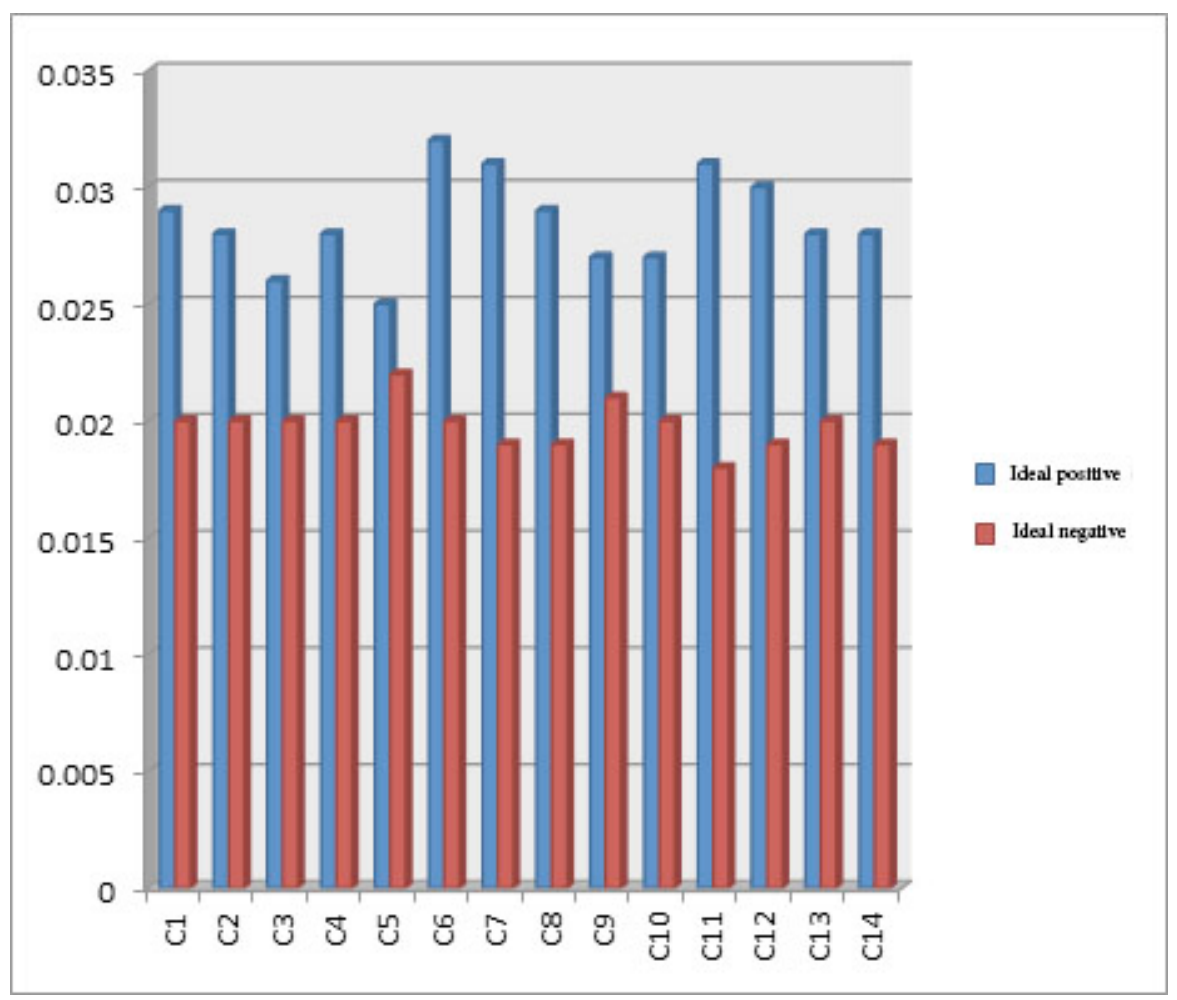

Figure 4: positive and negative ideal of each indicator

\section{Ø Rankings Options}

At this stage the options are rated based on CL values; In other words, any option that has higher CL may achieve better ranking. Table 11 shows the ranking of options.

Table11. Ranking options

\begin{tabular}{|c|c|c|c|c|c|}
\hline Rank & CL & distance to Negative ideal & distance to Positive ideal & Options & Raw \\
\hline 4 & 0.38 & 0.02 & 0.022 & A1 & 1 \\
\hline
\end{tabular}




\begin{tabular}{|c|c|c|c|c|c|}
\hline 3 & 0.421 & 0.008 & 0.031 & A2 & 2 \\
\hline 2 & 0.434 & 0.014 & 0.027 & A3 & 3 \\
\hline 1 & 0.585 & 0.016 & 0.022 & A4 & 4 \\
\hline 3 & 0.275 & 0.024 & 0.018 & A5 & 5 \\
\hline 6 & 0.376 & 0.028 & 0.013 & A6 & 6 \\
\hline
\end{tabular}

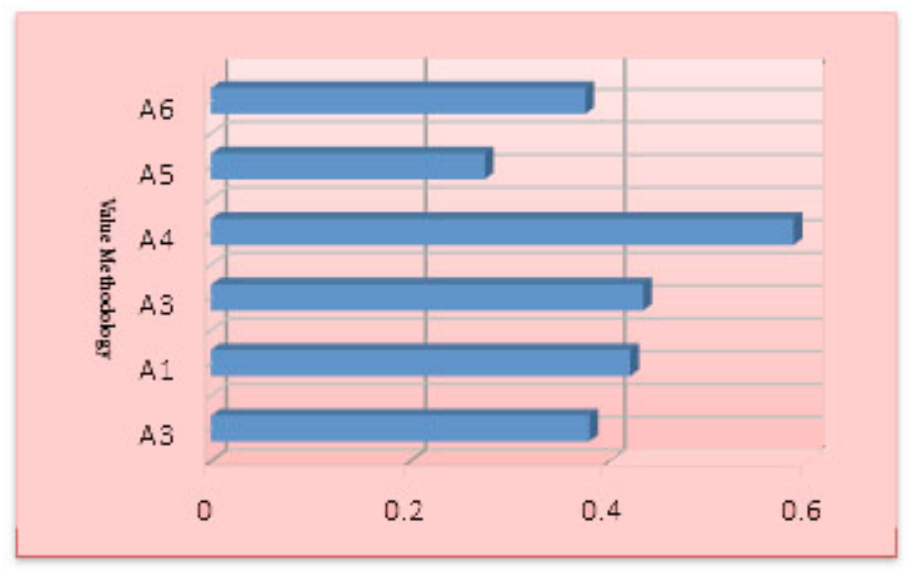

Figure5. Chart rankings Options

Finally, the results of options ranking using Topsis technique indicates that Value engineering methods using standard SAVE includes superior priority Iran's respect to other options. Figure 5 shows the ranking methods.

\section{CONCLUSION}

Different countries especially the developed countries have achieved great success by using value engineering techniques to save costs, increasing the efficiency, effectiveness, productivity, competitiveness and success in attracting a greater share of the market. In this regard, the requirement for generating culture and education in the implementation of value engineering in various fields, especially in the area of manufacturing industry in the country is sensed. Methodology have been considered value engineering positions at all levels of an organization from senior levels to staff level, encompassing brighter future than those methodologies which allocate less attentions to this issue. Value engineering experience made in Iran indicate that due to some unknown reasons acceptability and validity of value engineering is not confirmed which the main factor in this case, lack of completely understanding the different available methodologies concerning with value engineering.

In this paper in addition to introducing different methodologies of value engineering, six type of methodologies used in World are selected with assessment and analysis of required criteria for a value methodology and is evaluated through multi-criteria decision-making in TOPSIS which finally according to the experts viewpoints and the obtained results, it is observed that value engineering method using SAVE standard is appropriate option than the other 5 method for exploiting in projects within the country.

\section{REFERENCES}

Submit Date: 12.06.2016, Acceptance Date: 25.07.2016, DOI NO: 10.7456/1060AGSE/001

Copyright (C) The Turkish Online Journal of Design, Art and Communication 
Zimmerman, Larryz. PE. Glen D. hart, (1982) "Value engineering - A practical Approach for owners, Designers, and contractors", NEW Delhi, CBS Publishers.

Value Standard and Body of Knowledge SAVE International, The Value Society, Northbrook, IL, USA, June 2007.

Richard, P, (2008), value engineering, design and planning for the development, translation, Seyed Morteza Rihani, M. Golshan, S. Aminaei.

Karimi, M., (2008), undoubtedly improving: education of Value Engineering (Second Edition), Tehran, Institute of Cultural Services Rasa.

Pourreza, m., Zonnoorian, d. E, Atrii- (2010), value engineering knowledge, planning, Tehran's Press Center.

Instruction of value engineering studies, (2008), Vice President of Strategic Planning and Control.

Gholipour, Yaghoub and Beiraghi, "Foundations of Value Engineering", Tehran, Termeh Publisher, $1^{\text {st }}$ Edition.

Fodor Arpad, Fodor Valera, (1995), "the Beginning of the Implementation of Government", SAVE Proceeding.

US Army Corps of Engineers website.

http://www.leeds.ac.uk/civil/

AFAV: French Value Analysis Assocciation, www.afav.asso.fr/index/en.htm.

SCAV / CSVA: Canadian Society of Value Analysis, www.scav-csva.org.

IVM: The Institute of Value Management, www.ivm.org.uk.

VDI: The Association of Engineers, www.vdi.de/vdi/english/index.php.

INVEST: Indian Value Engineering Society, www.invest-in.org.

Value Engineering Study Methods Guide, (2014), Ports and Maritime Organization.

Holmes, S, (2008), "Better roads and bridges", Ministry of Transportation. 